\title{
Ecos do mundo dos artistas: memória e articulações comunicacionais
} Echoes of the world of artists: memory and communicational articulations

\section{Ecos del mundo de los artistas: memoria y articulaciones comunicacionales}

\author{
Maria Livia de Sá Roriz Aguiar ${ }^{1, a}$ \\ marialiviaroriz@gmail.com | http://orcid.org/oooo-0002-3013-8663 \\ ${ }^{1}$ Universidade Federal do Rio de Janeiro, Programa de Pós-Graduação em Comunicação e Cultura. Rio de Janeiro, \\ RJ, Brasil.
}

a Doutorado em Comunicação e Cultura pela Universidade Federal do Rio de Janeiro.

\section{RESUMO}

O trabalho apresenta as reflexões iniciais do projeto de pós-doutorado desenvolvido no Programa de PósGraduação em Comunicação e Cultura da Universidade Federal do Rio de Janeiro, que pretende ouvir artistas idosos de dois grupos distintos: no primeiro os sujeitos acometidos por patologias que afetam a memória, entre elas o Alzheimer, em suas fases iniciais; e no segundo sujeitos que se constroem e são construídos identitariamente como idosos, com base em seu lugar etário. Por meio de entrevistas, usando metodologicamente uma técnica que cruza os modos de fazer da história oral com os da entrevista clínica, realizaremos encontros com artistas (músicos, atores, artistas plásticos etc.) procurando perceber as vozes desses indivíduos como sujeitos de comunicação afetados pelo tempo (e, em alguns casos, pela doença).

Palavras-chave: Comunicação; Doença de Alzheimer; Barreiras de linguagem; Comportamento social; Processos mentais.

\begin{abstract}
The work presents the initial reflections of the postdoctoral project developed on the Graduate Program in Communication and Culture at Federal University of Rio de Janeiro, which intends to listen to old artists of two different groups: in the first, subjects affected by pathologies that affect the memory, including Alzheimer's, in its early stages; and in the second subjects who build and are built identically as old based on their age. Based on interviews, using the foundations of psychological clinic and oral history, we will hold meetings with artists (musicians, actors, visual artists, etc.) seeking to perceive the voices of these individuals as subjects of communication affected by time (and often by the disease).
\end{abstract}

Keywords: Communication; Alzheimer's disease; Language barriers; Social behavior; Mental processes. 


\section{RESUMEN}

El trabajo presenta las reflexiones iniciales del proyecto posdoctoral desarrollado con el Programa de Posgrado en Comunicación y Cultura de la Universidad Federal de Río de Janeiro, que pretende escuchar a artistas antiguos de dos grupos diferentes: en el primero, los sujetos afectados por patologías que afectan la memoria, incluido el Alzheimer, en sus primeras etapas; y el segundo sujetos que construyen y se construyen de manera idéntica a los ancianos, en función de su su edad. Mediante el uso de entrevistas, utilizando metodológicamente una técnica que cruza las formas de hacer historia oral con las de la entrevista clínica psicológica, mantendremos reuniones con artistas (músicos, actores, artistas visuales etc.) para percibir las voces de estas personas como sujetos de comunicación afectados por el tiempo (y a menudo por la enfermedad).

Palabras clave: Comunicación; Enfermedad de Alzheimer; Las barreras del idioma; Conducta social; Procesos mentales.

Contribuição dos autores:

Concepção e desenho do estudo: Maria Lívia de Sá Roriz Aguiar.

Aquisição, análise ou interpretação dos dados: Maria Lívia de Sá Roriz Aguiar.

Redação do manuscrito: Maria Lívia de Sá Roriz Aguiar.

Revisão crítica do conteúdo intelectual: Maria Lívia de Sá Roriz Aguiar.

Declaração de conflito de interesses: não há.

Fontes de financiamento: Coordenação de Aperfeiçoamento de Pessoal de Nível Superior - CAPES.

Considerações éticas: não há.

Agradecimentos/Contribuições adicionais: não há.

Histórico do artigo: submetido: 21 jan. 2020 | aceito: 16 jul. 2020 | publicado: 17 dez. 2020.

Apresentação anterior: não houve.

Licença CC BY-NC atribuição não comercial. Com essa licença é permitido acessar, baixar (download), copiar, imprimir, compartilhar, reutilizar e distribuir os artigos, desde que para uso não comercial e com a citação da fonte, conferindo os devidos créditos de autoria e menção à Reciis. Nesses casos, nenhuma permissão é necessária por parte dos autores ou dos editores. 


\section{INTRODUÇÃO}

Deve-se considerar, primeiramente, que a questão teórica da memória tem sido objeto de estudo frequente na área de ccomunicação não só no que diz respeito às memórias das mídias, mas também, de maneira mais ampla, à complexa problemática acerca do memorável, que pode ser entendida, do ponto de vista reflexivo, como uma questão de natureza comunicacional. O projeto com base no qual este artigo produz reflexões iniciais contempla articulações em torno das deficiências que podem ser atribuídas ao esquecimento, um dos traços constitutivos da memória. Denominada de 'Memórias por um fio', a investigação desenvolve reflexões levando em conta articulações comunicacionais memoráveis de pessoas idosas vinculadas sobretudo ao mundo do samba e acometidas ou não pelas chamadas patologias da memória, com o esquecimento indicando o seu lugar no mundo. Um dos vieses do trabalho é privilegiar sujeitos que, durante a sua existência, fizeram do mundo do samba lugar de localização e de construção de suas identidades. A morte, em muitos casos, não significa o apagamento completo; por anos, a produção do indivíduo e as suas histórias ecoarão nas paisagens do mundo e nas lembranças dos outros.

A pesquisa privilegiará, portanto, dois universos de 'velhos' sambistas: os poucos que são acometidos pela patologia que mais atinge a população idosa, o Alzheimer, que consiste em uma forma de demência que afeta a integridade física, mental e social dos sujeitos; e aqueles que seguem pela vida afora até idade avançada, lembrando cenas e personagens múltiplas também do mundo do samba que atravessaram suas existências.

A doença de Alzheimer tem como sintomatologia principal a perda de memória, contudo a degeneração acontece em três estágios: inicial, intermediário e final. Num sentido global, a etapa inicial dura de dois a quatro anos em média, com perda de memória recente e dificuldade progressiva das atividades diárias. $\mathrm{Na}$ fase intermediária, ocorre crescente perda de memória e principiam as dificuldades motoras, de linguagem e de raciocínio. Por fim, na fase terminal, as características principais são a restrição ao leito, o mutismo, o estado vegetativo e as contraturas ${ }^{1}$.

Esse quadro demencial não afeta somente o idoso, mas também os que estão em seu entorno. A patologia torna-se questão social, e a família apresenta-se como uma extensão da fala, da memória e da inserção desse sujeito no mundo. Interessa-nos, também, perceber como a família produz esse movimento e se transforma em guardiã dessa memória, podendo vir a salvaguardar a história de vida desse indivíduo.

\section{ARTICULANDO TEORIAS}

O quadro teórico proposto articula a questão da memória com a da identidade, privilegiando o esquecimento no que tange a um grupo de indivíduos mais 'velhos', os artistas, no momento em que são acometidos por uma doença que os coloca num movimento em direção ao esquecimento. Esse quadro abrange, principalmente, dois níveis de análise: a questão da memória ${ }^{2-6}$ em suas plurais compreensões; e a da velhice no que concerne à identidade ${ }^{7-10}$.

As identidades etárias, no que diz respeito ao grupo classificado como 'velhos', têm sido objeto de reflexões há décadasi. Na comunicação, também a relação identidade etária e produção comunicativa vem sendo conteúdo de múltiplas investigações, entretanto as patologias da memória só recentemente passaram a ser objeto de estudo mais aprofundado na comunicação. Como enfatiza Ana Paula Goulart Ribeiro ${ }^{11}$, de guardião das lembranças, o idoso passou a ser cada vez mais percebido como sujeito do esquecimento, ao ser acometido por doenças demenciais, das quais o Alzheimer é o exemplo mais emblemático.

A questão teórica da comunicação não é exclusiva de objetos que deixam ver de forma evidente nos seus processos. $\mathrm{Na}$ área da comunicação, estudam-se práticas e processos de sujeitos inseridos num

i Conforme, por exemplo, as reflexões de Guita Grin Debert ${ }^{7}$. 
mundo comum. Ao particularizarmos este grupo específico - o de idosos -, entendendo os processos nos quais se articulam os trabalhos da memória na produção do lugar em que eles ocupam hoje no mundo e percebendo a dimensão cognitiva (e suas estratégias de vinculação), estamos trabalhando numa perspectiva comunicacional.

Como explicita Muniz Sodré, a comunicação cobre "um largo, mas delimitado, espectro de ações e práticas" classificado em três níveis: veiculação, vinculação e cognição. Sobre a vinculação, o autor enumera como objeto de estudo as "práticas estratégicas de promoção ou manutenção do vínculo social, produzidas por ações comunitárias ou coletivas" ${ }^{12}$ (p. 234), pautadas por "formas diversas de reciprocidade comunicacional (afetiva e dialógica) entre os indivíduos"12 (p. 234). Já no que diz respeito à dimensão cognitiva, há que se considerar "as práticas teóricas relativas à posição de observação e sistematização das estratégias de vinculação"12 (p. 235).

Assim, a comunicação emerge não como disciplina, no sentido rigoroso do termo, mas como "uma maneira de pôr em perspectiva o saber tradicional sobre a sociedade, portanto, como um constructum hipertextual", isto é, um lugar de interface de saberes oriundos de diversos campos científicos, nos quais a questão da interpretação assume papel decisivo. A comunicação consiste, sobretudo, numa atividade crítica voltada para a "sociabilidade, a etnicidade e as práticas de socialização pela cultura": uma espécie de "filosofia pública" (p. 235), decreta Sodré13.

Na reflexão sobre os processos comunicacionais, o autor propõe a redescrição do conceito de comunicação como um comum, considerando o vínculo com o Outro, numa cadeia de reciprocidade, responsabilidade e compromisso. Estudar o grupo pressupõe, no nosso entendimento, uma reflexão sobre o Eu e o Outro, ação essencial na construção de um mundo partilhado, ou seja, na edificação de bases de um ato comunicacional extenso ${ }^{14}$.

Sodré destaca que esse ato se realiza num mundo comum, e que a comunidade redescrita é concebida não como um espaço próprio, mas como uma relação intersubjetiva, "que pode acontecer no interior da sociedade individualista moderna, de maneira velada ou esporádica”" ${ }^{14}$ (p. 196). A reciprocidade e a solidariedade, como formas de expressar e ver o Outro, são próprias desses laços que impõem "uma tarefa em comum" ${ }^{14}$ (p. 213). Para o autor, a comunidade (do latim communitas, que engloba, o que reúne, ou seja, o Eu e o Outro; e o dever, a obrigação e a dívida expressos no radical munus) não é uma substância (território, costumes, ideais políticos etc.) compartilhada, mas sempre uma dívida com o Outro impessoal.

Nesse sentido, o comum definido por Sodré aproxima-se da noção de conjuntividade proposta por Agnes Heller $^{15}$. Para a autora, não basta viver um mesmo tempo cronológico ou uma mesma época para sermos conjuntivos. A conjuntividade define-se quando há a percepção de uma partilha efetiva entre aqueles que vivem juntos, o que pressupõe a dimensão da comunicação e do cotidiano.

Definindo o sujeito da comunicação como aquele que vive, apalpa, sente e experimenta a comunicação, para Sodré esse sujeito é sempre um ser relacional e incompleto, aberto às múltiplas possibilidades interpretativas e também às incompletudes do pesquisador, que procura desvendar a complexidade de um mundo haja vista questões ordinárias, mas que podem ser guias para a compreensão das ações humanas.

Algumas reflexões teóricas pertencentes ao campo da psicologia, como o estudo dos processos cognitivos e dos sistemas afetivos e emocionais, nas teorias que sustentam a cognição humana, a emoção, entre outros que configuram o comportamento humano ${ }^{16}$, podem acrescentar nesta reflexão a dimensão cognitiva indispensável para a análise dos pressupostos comunicacionais.

Há que se destacar, ainda, a problemática dos vínculos. Latour, por exemplo, enfatiza que pensar a questão é colocar em contato os bons e maus vínculos que o sistema de relações constrói. Vínculo, para ele, "designa o que comove e coloca em movimento, fora da antiga tentativa de definir a ação a partir do dilema da determinação versus liberdade” ${ }^{\prime 17}$ (p. 33). 


\section{A questão da memória}

Esse comum partilhado e enunciado faz-se por estratégias narrativas que colocam em destaque jogos memoráveis. Num longo debate que começou no início do século XX, a conceituação teórica da memória repartiu-se numa visão que a considerava pertencente ao indivíduo e noutra que introduzia na sua definição a dimensão social. As reflexões de Sigmund Freud, em Recordar, repetir e elaborar ${ }^{18}$ e em Uma nota sobre o 'bloco mágico ${ }^{19}$, foram inaugurais e fundamentais para a construção do conceito.

Por outro lado, o sociólogo Maurice Halbwachs acrescentou que a dimensão social e coletiva é indispensável para se pensar a memória ${ }^{i i}$. A tradição dos estudos da memória seguiu no século XX duas direções: a primeira construiu a sociologia da memória com base nas formulações inauguradas por Halbwachs; já a segunda é dependente da tradição filosófica de Henri Bergson². De qualquer forma, ambas dialogavam diretamente com a psicanálise freudiana, uma vez que foi Freud que introduziu na clínica psicanalítica as necessidades de recordar, repetir e elaborar.

Ao longo do século XX, as reflexões em torno da questão assumiram múltiplas configurações. Lugares, restos, trabalhos, imagens, vestígios, farrapos, subterrâneos possíveis de sofrerem enquadramentos, memórias silenciadas e marginalizadas tornaram-se expressões síntese que acompanham diversas conceituações ${ }^{2,3,5,20-22}$.

Em Recordar, repetir e elaborar ${ }^{18}$, Freud apresenta a questão na dimensão do que denomina "lembranças encobridoras", relacionando-as ao ato suposto de lembrar ou de esquecer. Pela recordação, monta-se a história que figura numa lacuna. O recalcamento, ou seja, a produção de lembranças encobridoras ou lembranças não acionadas, é o ato suposto mais importante. Traz-se o esquecimento para a lembrança por meio da suspensão da repressão, e os buracos mnêmicos são preenchidos com as recordações. O esquecido nunca se transforma em lembrança; transforma-se em repetição, em ação. Repetir implica, pois, evocar um fragmento da vida real, sendo, portanto, revelação (e não registro) de algo que é vivido e representado psiquicamente. É ato, ação do presente $e^{\mathrm{iii}}$.

Considerando que a ação memorável (ou o "fazer-memória", de que fala Ricoeur) pressupõe o reconhecimento, no qual a fidelidade ao passado é apenas um desejo (um "voto"), a dimensão declarativa da memória visaria a uma memória feliz's.

A memória feliz consiste naquela que, pelo ato de reconhecer (mesmo que este se manifeste sob a forma de uma imagem e necessariamente tenha na fidelidade ao passado apenas o desejo), atribui "a si mesmo, aos próximos e aos longínquos" a figura do reconhecimento como materialidade de uma distância que se torna proximidade e reconcilia a minha memória com a de todos os outros que não eu e meus próximos. Sujeitos múltiplos da memória produzem a memória feliz, memória apaziguada, memória reconciliada, que, para Ricoeur, são então "as figuras da felicidade que nossa memória deseja para nós mesmos e para nossos próximos"5. É, então, no sentido de afectar, colocar uma marca que permite a exclamação 'É ela! É ele!', que explode pelo reconhecimento da memória, que a retenção de um mundo comum pode vir a ser expressa por imagenslembranças declarativas. São memórias que, podemos dizer, são afetadas.

"Afeto é o nome recente para o que antes se designava como afecção [...] deste modo, sendo affectio um estado do corpo afetado por outro presente, e o affectus, uma passagem de um estado a outro, são diferentes as afecções-imagens

\footnotetext{
ii A primeira edição de A memória coletiva é de 1925, embora a edição a que fazemos referência seja de 2006 . O artigo "La mémoire collective chez les musiciens", incluído na edição de A memória coletiva editada em 2006, no Brasil, é de 1939. Já a primeira edição de Quadros sociais da memória é de 1950.

iii No campo filosófico, é preciso considerar também as discussões de Henri Bergson², que construiu uma fenomenologia da lembrança. Grosso modo, podemos dizer que para o autor a imagem que se forma da ação mnêmica está sempre mediada pela imagem presente no corpo. A memória age fisicamente, nas reações do corpo sobre o ambiente, e opõe o que chama de percepção atual (a imagem aqui e agora do corpo, a matéria) ao que denomina lembrança. Com base na diferença entre percepção pura e memória, propõe a existência de duas memórias: a memória-hábito, do corpo, dos mecanismos motores; e a memória sonho bergsoniana, ou seja, lembranças isoladas e singulares.
} 
ou ideias dos afetos-sentimentos"15. Se, por um lado, o afeto supõe uma imagem ou uma ideia; por outro, ele não se reduz ao transitório nem ao representacional ${ }^{13}$.

Para Sodré, as afecções equivalem aos modos que se acham presentes tanto no corpo como no espírito. Nesse sentido, a memória feliz é a síntese das afecções, na maneira da extensão e na maneira do pensamento. Ampliando ainda mais o debate, o autor particulariza a questão das emoções, definindoas como "fundamentais para a 'máquina homeostática' do corpo. Do ponto de vista psicológico, sejam positivas ou negativas, elas estão aí, constituem a vida e têm de se expressar"13 (p. 51).

Aos portadores de Alzheimer, estão interditados a possibilidade memorável no estágio mais avançado da doença e o uso da memória como vínculo e afectação nos momentos iniciais em que as ligações do ser com a vida se fazem pelas lembranças que emergem de um passado mais longínquo. A memória torna-se essencial para a permanência de seus parcos vínculos com o mundo. A interdição da memória recente e a explosão da memória longínqua fazem deles sujeitos memoráveis numa dimensão particular em que o ato de lembrar e de esquecer se torna símbolo distintivo do ser-doente.

Ao não se reconhecer em atos memoráveis do presente ou do passado, nos vários estágios da doença, o paciente de Alzheimer tem impedido o reconhecimento e, portanto, a produção e elaboração de uma memória feliz. Sofre também com a perda da função elaborativa da memória, já que não é mais possível acessar os trânsitos em direção ao que ficou encoberto nas frestas de um passado que foi perdido, e é privado do ato de cura psicológica que se dá quando o sujeito pode recordar, repetir e elaborar. A ele está bloqueada a possibilidade de cura.

Por outro lado, em pesquisas anteriores ${ }^{22}$ observamos que os sambistas idosos têm um olhar peculiar em relação ao passado. Acionando o duplo lembrança/esquecimento do mundo do samba de maneira frequente e com características particulares - em festas, em reuniões, no ato múltiplo de estar juntos -, esses sujeitos constroem vínculos duradouros com o passado.

Em função disso, a pesquisa tem dupla face: debruça-se sobre aqueles que foram atropelados pela doença e sobre aqueles que mantêm os trabalhos de memória ativos, procurando perceber as ações memoráveis e como isso interfere e completa o estar no mundo desse grupo.

\section{UM OLHAR SOBRE A METODOLOGIA}

Vinciane Despret, no livro Ces émotions qui nous fabriquent ${ }^{24}$, revela a importância da questão da fabricação das emoções, destacando mais uma vez a ação dos agentes na produção de vínculos e na dimensão do sensível. É nesse sentido, também, que devemos pensar as relações que estabeleceremos com os sujeitos da pesquisa, pelos quais seremos afetados por ações e emoções.

Objetivamos seguir os rastros memoráveis esparsos e desconectados desses idosos, recuperando e reintroduzindo a dimensão das emoções que consideramos fundamentais para a análise. Devemos ter em mente a complexidade e a multiplicidade das 'coisas sociais', que se apresentam como modos de existência, ou, como diz Latour ${ }^{25}$, tais quais modos de conexão múltiplos e contraditórios. Assim, é essencial perceber a proeminência das emoções nesse mundo múltiplo e contraditório, onde tampouco há um quadro de análise dominante.

Identificado normalmente com silêncios impostos à sua fala, temos aqui, no caso dos sambistas acometidos pela doença, um grupo que se caracteriza por um papel contrário àquele que normalmente lhe é destinado: de guardiões da memória, transformam-se em seres sem memória.

Outra questão fundamental na pesquisa é a percepção do ser idoso. Compreendido como uma construção social, sobretudo com base nas proposições teóricas de diversos campos de conhecimento e cujos estudos podem ser qualificados como culturalistas, o envelhecimento foi alvo de um longo processo de apropriação e de ressignificações, muitas vezes com claros objetivos políticos. Portanto, as 
denominações dos que ultrapassavam dado período da vida foram transformando-se à medida que o mundo social também mudava.

Se com a eclosão dos padrões da modernidade - ênfase no individualismo e na razão - se produziu o processo de 'cronologização da vida', para alguns autores, no mundo contemporâneo, se vive a 'descronologização da vida'²6.

Observa-se também como o envelhecimento se tornou mecanismo essencial no processo de classificação e separação dos seres humanos, produzindo conflitos e levando à criação de mecanismos de controle de natureza homogeneizante, sem considerar, por exemplo, as diferenças de classe, de gênero e de etnia.

Debert propõe pensar o tema do envelhecimento com base numa posição política que pondere sobre como as modificações nas representações acerca do envelhecimento rearticulam projetos de vida, de trabalho, de lazer e de consumo desses grupos, bem como a reestruturação do cuidado informal dos mais velhos diante das políticas públicas específicas, compreendendo as formas de gestão da velhice que paulatinamente saem do âmbito privado e familiar para se transformar em questão pública7.

Tomamos como pressuposto metodológico central a ideia de que a teoria/metodologia a ser adotada advém das práticas. Igualmente, as práticas serão objeto da observação minuciosa que realizaremos. Observações, escutas, participações, narrativas que se deixam ver nas práticas. A questão metodológica principal é: que mecanismos podemos acionar para entrevistar esse grupo que com doenças de memória apresenta limitações e interdições na ordem memorável?

A princípio, para as entrevistas usaremos o cruzamento entre os pressupostos da história oral, quando produzem metodologicamente as histórias de vida, e a prática da escuta clínica da psicologia. Acreditamos que essa conjugação seja mais eficiente, pois sabemos das limitações impostas pela doença na memória declaratória das personagens. E também compreendemos a importância de outros sujeitos na complementação dessa lembranças permeadas sempre pelas figuras do esquecimento.

Cabem algumas considerações sobre a questão das histórias de vida como possibilidade de construir uma arquitetura metodológica em torno das entrevistas. Utilizadas sobretudo com base nos pressupostos teóricos e metodológicos da história oral, as histórias de vida tornam-se uma oportunidade de reconstruir caminhos e trilhas em busca de uma interpretação. A entrevista transforma-se em diálogo comunicacional que revela subjetividades e estabelece elos entre o entrevistado e o entrevistador.

Nas histórias de vida é a ação viva da memória que produz os dados empíricos fundamentais para a interpretação. O historiador Alessandro Portelli ${ }^{27}$ define história oral como uma arte, a reconstrução da vida por intermédio da narrativa, o processo de escutar as vozes das pessoas comuns, de dar voz aos que, em princípio, não a teriam. Trata-se de uma metodologia centrada no movimento de ouvir o Outro, permitindo conhecer a trajetória de atores vivos.

Assim, a história oral não deve ser considerada apenas um método. É, sobretudo, uma dimensão teórica, cujos parâmetros devem ser observados, também, na dimensão técnica da metodologia. Agrega modos de fazer e teoria, sendo uma metodologia, uma interpretação e uma teoria em relação a determinado objeto de pesquisa ${ }^{28}$. Ganham relevo os conteúdos da memória, evocados e organizados, numa troca viva e ativa entre entrevistado e entrevistador ${ }^{29}$.

Logo, propomos para a realização metodológica da pesquisa, na sua dimensão metódica, o cruzamento das técnicas da história oral com os modos de escuta utilizados na clínica analítica, em que a produção do tempo de realização (e elaboração interpretativa) e a forma como se escuta ocupam lugares-chave.

$\mathrm{Na}$ história oral, na transferência da memória há, muitas vezes, a eclosão de uma memória oriunda da herança de fatos vividos, por exemplo, pelos ascendentes e que, na narrativa, é construída pelo sujeito testemunhado. Os entrevistados apropriam-se de fatos, imagens, descrições vividas por seus pais, familiares e pessoas próximas e com esses dados constroem a sua própria história - e a história familiar e a do grupo aparecem como parte da sua trajetória individual. É o movimento de fazer parte de histórias, mesmo que 
na ausência, construindo, assim, um pertencimento ao grupo referenciado mediante uma cadeia de fatos memoráveis. No âmbito clínico, esse acionamento ocorre mais em outro tempo e com outras ações. Esse é apenas um exemplo das aproximações e dos distanciamentos entre as possibilidades de modos de realização dessas entrevistas ${ }^{\text {iv }}$.

Emergirão espécies de memórias colaborativas nas quais as falas daqueles que vivem ao lado do indivíduo completarão as lacunas das possibilidades de lembrança. Se a trajetória de vida daquela pessoa, o percurso de artista, pode recuperar ecos da vida no passado; por outro lado, é preciso estar atento àqueles que, no presente, desempenham o papel de porta-voz (autorizados ou não), que falam por ele e como ele. Portanto, as técnicas que governam o sentido metodológico da história oral deverão ser, num certo sentido, reatualizadas, já que os silêncios também ganharam significações complementares nas falas de outros que se constituem como suportes da lembrança daqueles que não podem mais lembrar.

A dificuldade das entrevistas é a impossibilidade do testemunho, o que afeta o posicionamento do sujeito enquanto ser no mundo. No grupo considerado, pode-se perder, em alguns casos, qualquer tipo de possibilidade testemunhal e, em consequência, perde-se não apenas a posição memorável em relação ao passado, mas o que se refere ao presentev .

Na metodologia, o encontro e a troca dialógica são aportes fundamentais para a reconstrução dos atos vividos. Coletar os dados requer o encontro, as trocas, as performances, a captação de materiais que estão além do ato narrativo em si. Se alguns dos sujeitos desta pesquisa passam por um processo degenerativo que afeta a parte motora, cognitiva, mnemônica, algumas questões ficam postas: como capturar essas histórias de vida? De que modo coletar os dados? Como realizar as entrevistas? Quais são os porta-vozes desses sujeitos? Como capturar as lembranças deles, sujeitos em processos degenerativos de memória?

Em nossa hipótese, é nas redes de apoio (nas quais outros sambistas também ocupam lugar central) que a manutenção da memória se dá. Mas talvez seja nos ecos da existência artística, a partir do que a arte deixou nas vidas deles e dos Outros, que podemos perceber o lugar privilegiado da sobrevivência da mais intensa conexão memorável.

O relato visa à construção de outro texto. Da fala do entrevistado nasce a escrita do entrevistador. É a construção de uma história não só pela fala, mas pelo lugar em que ocorreu a entrevista, pelos momentos e pelos gestos observados. Uma história que tem seu ponto nodal na narrativa e que, no entanto, conta também com outros elementos para sua interpretação.

\section{CONSIDERAÇÕES FINAIS}

Norbert Elias, em seu livro 'A solidão dos moribundos', afirma que a velhice representa concretamente o fim, a falta de controle: "A morte é um dos fatores que indica que o controle humano sobre a natureza tem limites"9 (p. 53).

Alguns desafios se apresentam ao utilizar a metodologia da história oral: como coletar os dados? Como se dá a captação das histórias? Quem narra os fatos do passado? Quem se torna detentor dessa memória? Ao delegar a outros a continuação da memória, esses sujeitos nomeiam o Outro como detentor das suas próprias histórias, que serão produzidas a partir desses novos detentores, mas também por meio de brechas, de falas e gestos desses idosos.

iv Para o aprofundamento dessa questão, ver Aguiar ${ }^{23}$.

v Para Pollak ${ }^{21}$, a memória é sempre posicionada, isto é, aquele que recorda sempre o faz de um lugar transitório e em função dos interesses que possui naquele momento específico. Há que se considerar também, com base nas principais contribuições de Halbwachs, que a memória é sempre do presente. 
Nesse momento em que ainda tateamos o campo da pesquisa a ser descoberto, precisamos particularizar a forma como será usada a história oral e os limites que se apresentam no caso desta análise. Com base nos fragmentos narrativos, nas junções e nas complementações da memória, objetivamos tecer histórias.

Assim, acreditamos que a ausência da capacidade mnemônica, para o segmento da pesquisa que sofre de patologias que afetam a memória, não será o único limitador, já que as pessoas que vivem com as 'patologias da memória' convivem com um conjunto de barreiras que afetam o mental, o cognitivo, o perceptivo e o motor.

Nesta proposta de trabalho, iniciamos o percurso da pesquisa problematizando as provocações em relação ao objeto analisado. Enfrentaremos os desafios das barreiras subjetivas e objetivas, procurando ao longo desse processo construir uma história narrada por esses idosos a partir do lugar deles no mundo como artistas.

\section{REFERÊNCIAS}

1. Valim MD, Damasceno DD, Abi-acl LC, Garcia F, Fava SMCL. A doença de Alzheimer na visão do cuidador: um estudo de caso. Rev Eletrôn Enferm [Internet]. 2010 [citado em 2019 out. 26];2:528-34. Disponível em: https://www.fen.ufg.br/revista/v12/n3/v12n3a16.htm.

2. Bergson H. Matéria e memória: ensaios sobre a relação do corpo com o espírito. São Paulo: Martins Fontes; 1999.

3. Huyssen A. Seduzidos pela memória. Rio de Janeiro: Artiplano; 2000.

4. Halbwachs M. A memória coletiva. São Paulo: Vértice; 2006.

5. $\quad$ Ricoeur P. A memória, a história, o esquecimento. Campinas: Unicamp; 2008.

6. Sarlo B. Tempo passado: cultura da memória e guinada subjetiva. São Paulo: Companhia das Letras; Belo Horizonte: Editora da UFMG; 2007.

7. Debert GG. A reinvenção da velhice: socialização e processos de reprivatização do envelhecimento. São Paulo: Edusp; FAPESP; 1999.

8. Beauvoir S. A velhice: realidade incômoda. São Paulo: Difusão Europeia do Livro; 1970.

9. Elias N. A solidão dos moribundos. Rio de Janeiro: Jorge Zahar; 2001.

10. Moreira MD, Caldas CP. A importância do cuidador no contexto da saúde do idoso. Rev Escola Anna Nery [Internet]. 2007;11(3):520-5. doi: http://dx.doi.org/10.1590/S1414-81452007000300019.

11. Ribeiro APG. Patologias da memória: testemunhos, mídia e velhice [projeto de pesquisa]. Rio de Janeiro; 2019. Co-financiado por CNPq e FAPERJ.

12. Sodré M. Antropológica do espelho: uma teoria da comunicação linear e em rede. Petrópolis: Vozes; 2011.

13. Sodré M. As estratégias sensíveis: afeto, mídia e política. Vozes, 2006.

14. Sodré M. A ciência do comum: notas para o método comunicacional. Vozes, 2013.

15. Heller A. Uma teoria da história. Rio de Janeiro: Civilização Brasileira; 1993.

16. Arendt R. Psicologia comunitária: teoria e metodologia. Psicol Reflex Crít. 1997;10(1):7-16.

17. Latour B. The promises of construtivism. In: Idhe D, Selinger E, editors. Casing technoscience: matrix of materiality. Indiana: Indiana University Press; 2002. p. 27-43.

18. Freud S. Edição standard brasileira das obras psicológicas completas de Sigmund Freud. Vol. 12. Recordar, repetir e elaborar. Rio de Janeiro: Imago; 1980. p. 191-203.

19. Freud S. Obras psicológicas completas. Vol. 16. Uma nota sobre o 'bloco mágico'. São Paulo: Companhia das Letras; 2011. p. 267-74.

20. Nora P. Les lieux de mémoire. Paris: Gallimard; 1984. 
21. Pollak M. Memória e identidade social. Estud Hist [Internet]. 1992 [citado em 2020 set. 28];5(10):20012. Disponível em: https://bit.ly/30ck6go.

22. Pollak M. Memória, esquecimento, silêncio. Estud Hist [Internet]. 1989 [citado em 2019 dez. 01];2(3):315. Disponível em: https://bit.ly/33aInW3.

23. Aguiar MLSR. Homens memória: a Velha Guarda e a guarda das tradições do samba carioca [dissertação]. Rio de Janeiro: Universidade do Estado do Rio de Janeiro; 2013.

24. Despret V. Ces émotions qui nous fabriquent: ethnopsychologie de l'authenticité. Paris: Synthelabo; 1999.

25. Latour B. Dialogue sur deux systèmes de sociologie. In: Breviglieri M, Lafaye $C$, Ttrom $D$, editors. Sens de la justice, sens critique [Internet]. Paris: Economica; 2009 [cité dans 2019 déc 19]. p. 359-90. Disponible en: http://www.bruno-latour.fr/sites/default/files/95-DIALOGUE-GSPM-CSI.pdf.

26. Held T. Institutionalization and deinstitutionalization of the life course. Hum Dev. 1986;29(3):157-62.

27. Portelli A. Tentando aprender um pouquinho: algumas reflexões sobre a ética na história oral. Proj Hist. 1997 abr.;(15):13-49.

28. Amado J, Ferreira MM, organizadores. Usos e abusos da história oral. Rio de Janeiro: Editora FGV; 2006.

29. Portelli A. Ensaios de história oral. São Paulo: Letra e Voz; 2010. 